\title{
Análise morfológica e funcional do processo espermatogênico em cobaios (Cavia porcellus) da pré-puberdade até a pós-puberdade ${ }^{1}$
}

\author{
Amanda K.R. Nunes², Bruna B. Gouveia², Maria Helena T. Matos², Isabelle Caroline \\ Pires $^{2}$, Vanessa S. Franzo ${ }^{3}$, Marcelo D. Faria ${ }^{2}$ e Adriana Gradela ${ }^{2 *}$
}

\begin{abstract}
Nunes A.K.R., Gouveia B.B.., Matos M.H.T., Pires I.C., Franzo V.S., Faria M.D. \& Gradela A. 2013. [Morphological and functional analysis of spermatogenesis in guinea pigs (Cavia porcellus) from pre-puberty to post-puberty.] Análise morfológica e funcional do processo espermatogênico em cobaios (Cavia porcellus) da pré-puberdade até a pós-puberdade. Pesquisa Veterinária Brasileira 33(Supl.1):1-7. Colegiado de Medicina Veterinária, Fundação Universidade Federal do Vale do São Francisco, Rodovia 407 Km 12, Lote 543, Projeto Nilo Coelho C1, Petrolina, PE 56300-000, Brazil. E-mail: agradela@hotmail.com

This study describes the morphological and functional analysis of spermatogenesis in guinea pigs (Cavia porcellus) with five (W5), six (W6), nine (W9) and eleven (W11) weeks of age ( $n=5 /$ group). The aspects analyzed include counts of cell populations present in stage 1 of seminiferous epithelium cycle (SEC), efficiency of spermatogonial mitosis (EMi), meiotic production (EMe), overall yield of spermatogenesis (EOS), Sertoli cell index (SCI) and carrying capacity of Sertoli cells (CCSC). The results showed that the average number of spermatogonia type A, primary spermatocytes in pré-leptóteno/leptóteno, primary spermatocytes in pachytene, total spermatogenic cells and Sertoli cells showed numerical variations according to age; however they were statistically not detected, while round spermatids increased significantly at puberty and then stabilized. The spermatogenic production of 5 to 11-week-old guinea pigs did not reach the stabilization point, and the RMi, RME, EOS, SCI and CCSC showed significant number variation as a function of age. The results demonstrate that Cavia porcellus in post-pubertal stage 2 are an advantageous experimental model to address studies on the processes of homologous recognition, alignment, and synapsis during meiotic prophase; intrinsic yield of spermatogenesis in guinea pigs is similar to Wistar rats, paca and agouti (Dasyprocta sp.) and lower than in cavies, whereas the functional efficiency of Sertoli cells is higher than in agouti and Wistar rats, and lower than in pacas, spiny rat and collared peccaries. We conclude that in guinea pigs the spermatogenesis is fully established at 6 weeks of age, indicating the pubertal stage of sexual development, and until week 11 they do not reach the maximum daily sperm production and therefore sexual maturity.
\end{abstract}

INDEX TERMS: Guinea pig, Cavia porcellus, spermatogenesis, testicle, seminiferous tubule.

RESUMO.- Este estudo descreveu as análises morfológica e funcional do processo espermatogênico em cobaios (Cavia porcellus) de cinco (S5); seis (S6); nove (S9) e onze (S11)

\footnotetext{
${ }^{1}$ Recebido em 23 de setembro de 2013.

Aceito para publicação em 8 de novembro de 2013.

${ }^{2}$ Colegiado de Medicina Veterinária, Fundação Universidade Federal do Vale do São Francisco (Univasf), Rodovia $407 \mathrm{Km} \mathrm{12,} \mathrm{Lote} \mathrm{543,} \mathrm{Projeto}$ Nilo Coelho C1, Petrolina, PE 56300-990, Brasil. *Autor para correspondência: agradela@hotmail.com

${ }^{3}$ Laboratório de Anatomia Animal, Faculdade de Agronomia e Medicina Veterinária (Famev), Universidade Federal do Mato Grosso (UFMT), Av. Fernando Correa da Costa 2367, Boa Esperança, Cuiabá, MT 78060-900, Brasil.
}

semanas de idade ( $\mathrm{N}=5$ /grupo). Os aspectos analisados incluíram a contagem das populações celulares presentes no estádio 1 do ciclo do epitélio seminífero (CES), eficiência das mitoses espermatogoniais (RMi), produção meiótica (RMe), rendimento geral da espermatogênese (RGE), índice de células de Sertoli (ICS) e capacidade de suporte das células de Sertoli (CSCS). Os resultados mostraram que número médio de espermatogônias $\mathrm{A}$, espermatócitos primários em pré-leptóteno/leptóteno, espermatócitos primários em paquíteno, células espermatogênicas totais e células de Sertoli mostraram variações numéricas em fun- 
ção da idade, entretanto, não detectadas estatisticamente, enquanto espermátides arredondadas aumentaram significativamente na puberdade e depois se estabilizaram. A produção espermatogênica de cobaios de 5 a 11 semanas não atingiu o ponto de estabilização e o RMi, RMe, RGE, ICS e CSCS mostraram variação numérica significativa em função da idade. Os resultados demonstraram que Cavia porcellus na pós-puberdade 2 são um modelo experimental vantajoso para estudos de processos de reconhecimento homólogos, alinhamento, e sinapses durante a prófase meiótica; o rendimento intrínseco da espermatogênese em cobaios é semelhante ao relatado para ratos Wistar, pacas e cutias (Dasyprocta sp.) e menor do que em preás, enquanto que a eficiência funcional das células de Sertoli é superior a de cutias e ratos Wistar e inferior à de pacas, rato espinhoso e catetos. Concluiu-se que em cobaios a espermatogênese está completamente estabelecida na semana 6 de idade, indicando a fase púbere do desenvolvimento sexual, e até a semana 11 eles não atingiram a produção espermática diária máxima e, portanto, a maturidade sexual.

TERMOS DE INDEXAÇÃO: Cobaios, Cavia porcellus, espermatogênese, testículo, túbulo seminífero.

\section{INTRODUÇÃO}

A função reprodutiva é um fator de vital compreensão tanto para estabelecimento de sistemas apropriados de manejo quanto para o uso de espécies como modelo animal em estudos reprodutivos. Neste sentido, o conhecimento da espermatogênese, definido como um processo sincrônico e regular de diferenciação celular pelo qual uma espermatogônia tronco é gradativamente diferenciada numa célula haploide altamente especializada, o espermatozóide (França \& Russell 1998), é importante para a identificação das causas potenciais de infertilidade e subfertilidade e compreensão dos processos que definem a capacidade de produção espermática (Aguiar et al. 2006).

A espermatogênese ocorre no túbulos seminífero, o qual, na maioria das espécies, é o principal componente do parênquima testicular. Considerando-se que a massa testicular reflete diretamente a produção espermática, a variação na proporção de túbulos seminíferos entre as diversas espécies pode ser considerada como um dos principais fatores responsáveis pela diferença observada na eficiência da produção espermática. Embora a atividade espermatogênica seja relativamente constante em animais sexualmente maduros, não sazonais, ela apresenta variações expressivas entre as espécies e entre as linhagens ou raças (França \& Russell 1998). Neste sentido, a quantificação histológica do parênquima testicular torna-se essencial para os estudos envolvendo parâmetros reprodutivos, pois se constitui em um instrumento acurado para avaliação da capacidade espermatogênica dos animais, tanto em condições de normalidade, como patológicas ou experimentais (Cardoso 2009).

Além disso, os estágios iniciais da prófase meiótica, leptóteno e zigóteno, são importantes porque cromossomos homólogos se reconhecem, alinham e pareiam durante eles. Todavia em túbulos seminíferos de espécies mamíferas eles são pobremente representados dificultando a execução de estudos voltados para estes estágios e tornando as bases moleculares destes eventos pouco conhecidas e compreendidas em eucariotas superiores (Rodríguez \& Wettstein 2004).

Por ser extremamente sensível a tratamentos quimioterápicos, hormonais e à temperatura e pelo fato de que a recuperação da produção espermática é dependente da regeneração das células-tronco, a espermatogênese tem sido estudada em diversas espécies como os roedores, pois sua extraordinária capacidade reprodutiva em uma grande variedade de condições climáticas (Myers 2000), os torna importantes em muitos ecossistemas (Ferreira et al. 2007) e lhes garante importância em pesquisas biomédicas e em testes laboratoriais. Dentre eles o cobaio (Cavia porcellus, Linnaeus, 1758) tem sido utilizado com este fim desde o final do século 18 com importância crescente nas pesquisas científicas, pois seu longo período de gestação, ovulação espontânea e corpo lúteo ativo tornam-no um excelente modelo animal para estudo de reprodução humana (Suzuki et al. 2003).

Em cobaios machos a fisiologia reprodutiva é pouco estudada, destacando-se estudos voltados na quantificação dos tipos celulares nas diferentes fases sexuais em cobaios Dunkin Hartley (Rodríguez \& Wettstein 2004) e nas glândulas acessórias em Cavia porcellus (Vásquez \& Del Sol 2010, Gradela et al. 2012). Por isso, torna-se necessário um estudo mais detalhado sobre a espermatogênese nestes para que ocorra um melhor entendimento desta espécie em termos reprodutivos e para viabilizar sua utilização como modelo animal em estudos reprodutivos.

0 presente estudo objetivou analisar morfológica e funcionalmente o processo espermatogênico em cobaios ( $\mathrm{Ca}$ via porcellus) desde a pré-puberdade até a pós-puberdade (Gradela et al. 2012). Para tanto se avaliou as populações celulares presentes no epitélio seminífero no estádio 1 do CES, a taxa intrínseca de espermatogênese, o índice de células de Sertoli, a eficiência das mitoses espermatogoniais, a produção meiótica e a capacidade de suporte das células de Sertoli.

\section{MATERIAL E MÉTODOS}

Foram utilizadas amostras testiculares de 20 cobaios (Cavia porcellus), nascidos e criados no biotério da Universidade Federal do Vale do São Francisco em Petrolina, Estado de Pernambuco, Brasil (Latitude: $09^{\circ} 23^{\prime} 55^{\prime \prime} /$ Longitude: $40^{\circ} 30^{\prime} 03^{\prime \prime} /$ Altitude $376 \mathrm{~m}$ ), com idades de cinco (S5) semanas correspondendo a fase pré-púbere tardia, seis (S6) semanas correspondendo a fase púbere, nove (S9) semanas correspondendo a fase pós-púbere 1 e onze (S11) semanas correspondendo a fase pós-púbere 2 (N=5/grupo etário). Este estudo foi aprovado pelo Comitê de Ética Experimental em Humanos e Animais (CEEHA) da Univasf sob protocolo no22041019. Os espécimes foram desmanados na quarta semana de idade, quando receberam água e ração comercial ad libitum, até o momento da avaliação.

Ao atingirem a idade programada, os cobaios foram anestesiados com cloridrato de xilazina e cloridrato de ketamina na diluição $1: 5(0,1 \mathrm{ml} / 100 \mathrm{~g} \mathrm{PV})$ associados ao cloridrato de tramadol (2mg/1000g) [IM] e eutanasiados por exanguinação por punção da veia cava caudal. Fragmentos testiculares foram colhidos, fixados em formalina tamponada a $10 \%$ por $18 \mathrm{~h}$ e imersos em álcool $70 \%$ até o processamento histológico de rotina, quando 
foram emblocados em parafina, submetidos a cortes histológicos de $7 \mu \mathrm{m}$ de espessura em micrótomo EasyPath, São Paulo, Brasil e, após serem desparafinizados e reidratados, foram corados com hematoxilina de Mayer. Após desidratação gradual em etanol a $70 \%$ e $95 \%$, os cortes foram ainda corados em tampão eosina antes de serem montados (Silva et al. 2001). As lâminas depois de coradas e montadas foram analisadas em microscópio binocular Olympus BX 50, equipado com câmera digital.

Quantificação das células espermatogênicas. Foram avaliados apenas túbulos seminíferos no estádio 1 do ciclo do epitélio seminífero (CES) de acordo com o método da morfologia tubular que os classifica em 8 estádios (Courot et al., 1970), por isso, cobaios impúberes (S1 e S2) e pré-púberes iniciais (S3 e S4) não foram avaliados. Desta forma, para a quantificação das células espermatogênicas e das células de Sertoli foram analisadas 10 secções transversais de túbulos seminíferos, em cada animal nas fases púbere e pós-púbere (S6 a S11) e 20 secções transversais nos animais na fase pré-púbere tardia (S5).

Em cada célula da linhagem espermática (espermatogônias, espermatócitos e espermátides arredondadas) e nas células de Sertoli foram obtidas as médias entre os eixos X (maior) e Y (menor) dos núcleos e nucléolos, respectivamente. Em seguida, as quantificações foram submetidas a um fator de correção de acordo com a objetiva, sendo utilizada uma lente micrométrica. A contagem obtida no interior das secções transversais dos túbulos seminíferos para cada tipo celular foi corrigida para a espessura do corte e diâmetro nuclear e/ou nucleolar médio e a espessura do corte segundo a fórmula de Abercrombie (1946) corrigida por Amann (1962).

Avaliação do rendimento da espermatogênese e índice de célula de Sertoli por total de células espermatogênicas. A avaliação do rendimento da espermatogênese é a razão entre os tipos celulares estudados e divide-se em rendimento mitótico, rendimento meiótico e rendimento geral da espermatogênese. 0 rendimento mitótico ou coeficiente de eficiência das mitoses foi calculado pela razão entre espermatócito primário jovem em pré-leptóteno/leptóteno e espermatogônia A (RMi= PL/L:SPGA); o rendimento meiótico pela razão entre espermátides arredondadas e espermatócitos primários em paquíteno (RMe= SPDAr:PQ) e o rendimento geral da espermatogênese pela razão entre espermátides arredondadas e espermatogônias (RGE= SPDAr:SPGA).

0 índice de célula de Sertoli (ICS) foi calculado a partir da razão existente entre estas células e as espermátides arredondadas (ICS= SPDAr:CS).

Avaliação da capacidade de suporte das células de Sertoli (CSCS). Para avaliar a capacidade de suporte das células de Sertoli (CSCS) foi calculada a razão entre o número total de células de Sertoli (CS) e o número total das células espermatogênicas (CE) (CSCS= CE:CS).

Análise estatística. Os dados distribuíram-se de forma paramétrica (teste de normalidade de Kolmogorov Smirnov P>0,10) e o teste estatístico denominado ANOVA (com post hoc Teste de Tukey) permitiu analisar as diferenças entre as variáveis. 0 teste de Coeficiente de Correlação Simples foi aplicado para medir o grau de correlação linear entre duas variáveis numéricas, correspondentes aos valores entre cada tipo de células espermatogênicas e células de Sertoli em cobaios com cinco, seis, nove e onze semanas de idade. Todo o processamento estatístico foi realizado sob o suporte computacional ASSISTAT 7.6 beta.

\section{RESULTADOS}

O presente estudo avaliou morfológica e funcionalmente o processo espermatogênico em 20 cobaios (Cavia porcellus) agrupados de acordo com a fase do desenvol- vimento sexual. As espermatogônias do tipo A (SPGA), não apresentaram alterações significativas nas semanas estudadas, variando de $1,46 \pm 1,12$ na pré-puberdade tar-

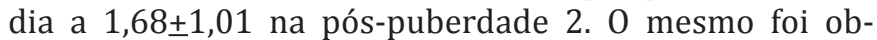
servado com os espermatócitos I em pré-leptóteno/lep-

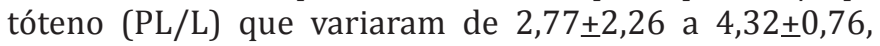
respectivamente; total de células espermatogênicas (CE) $(4,29 \pm 5,30$ a 7,73 $\pm 6,29)$; células de Sertoli (CS) $(1,67 \pm 1,22$ a $2,05 \pm 0,72$ ) e espermatócitos I na fase de paquíteno (PQ) $(8,22 \pm 6,18$ a $7,81 \pm 2,30)$. Por outro lado, as espermátides arredondadas (SPDAr) aumentaram significativamente,

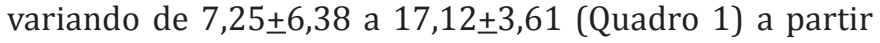
da fase púbere indicando a maior atividade do processo espermatogênico.

CS apresentaram características morfológicas de maturidade desde a fase pré-púbere tardia.

A quantificação de espermatogônias A, espermatócitos primários em $\mathrm{PL} / \mathrm{L}$, espermatócitos primários em PQ e SPDAr em relação ao total células espermatogênicas em túbulos seminíferos de cobaios é mostrada no Quadro 2. Apenas a porcentagem de SPDAr foi menor significativamente na fase pré-púbere em relação as demais fases. 0 Quadro 3 exibe a quantificação de espermatócitos primários em pré-leptóteno/leptóteno (PL/L) e paquíteno (PQ) em relação ao total de espermatócitos primários em PL/ L+PQ analisados. Nota-se que a quantidade de espermatócitos primários em PL/L foi significativamente menor que a de espermatócitos primários em PQ em todas as fases do desenvolvimento sexual.

0 rendimento geral da espermatogênese (RGE) e o RMi aumentaram significativamente a partir da fase pós-púbere 1 , tendo o RGE variado de 4,19 a 17,42 e o RMi de 1,25 a 4,26 ; enquanto que o $\operatorname{RMe}(0,73$ a 2,55$) ;$ o $\operatorname{RGE}(4,19$ a $17,42)$; o ICS $(3,24$ a 10,32$)$ e a $\operatorname{CSCS}(11,78$ a 17,14$)$ aumentaram significativamente a partir da fase púbere (Quadro 4). O RMi e o RGE apresentaram um desenvolvimento crescente (Fig.1), enquanto o RMe, o ICS e a CSCS foram incialmente crescentes e depois decrescentes (Fig.2), o mesmo tendo sido observado com o ICS e CSCS.

Correlação linear significativa foi observada na fase pré-púbere tardia entre SPGA e PL/L $(r=0,95, P<0,01)$;

Quadro 1. Números corrigidos* de células por secção transversal de túbulo seminífero de cobaios (Cavia porcellus) de cinco, seis, nove e onze semanas de idade

\begin{tabular}{|c|c|c|c|c|}
\hline \multirow[t]{2}{*}{ Tipos celulares } & \multicolumn{4}{|c|}{ Idade (semanas) } \\
\hline & S5 & S6 & S9 & S11 \\
\hline Espermatogônia A & $1,46+1,12^{\mathrm{a}}$ & $1,43+0,67^{\mathrm{a}}$ & $1,27+0,90^{\mathrm{a}}$ & $1,68+1,01^{\mathrm{a}}$ \\
\hline $\begin{array}{l}\text { Espermatócito primário } \\
\text { em pré-Leptóteno/Leptóteno }\end{array}$ & $2,77+2,26^{a}$ & $3,76+1,49^{a}$ & $3,97+1,26^{a}$ & $4,32+0,76^{a}$ \\
\hline $\begin{array}{l}\text { Espermatócito primário } \\
\text { em paquíteno }\end{array}$ & $8,22+6,18^{a}$ & $6,60+1,72^{a}$ & $8,17+3,76^{a}$ & $7,81+2,30^{\mathrm{a}}$ \\
\hline Espermátide arredondada & $7,25+6,38^{a}$ & $17,28+4,92^{\mathrm{b}}$ & $15,02+4,53^{b}$ & $17,12+3,61^{b}$ \\
\hline $\begin{array}{l}\text { Total de Células } \\
\text { espermatogênicas }\end{array}$ & $4,29+5,30^{a}$ & $7,45+6,65^{a}$ & $7,29+5,98^{a}$ & $7,73+6,29^{a}$ \\
\hline Células de Sertoli & $1,67+1,22^{\mathrm{a}}$ & $1,69+0,22^{\mathrm{a}}$ & $1,69+0,60^{\mathrm{a}}$ & $2,05+0,72^{\mathrm{a}}$ \\
\hline
\end{tabular}

*Correção segundo Abercrombie (1946) corrigido por Amann (1962). a,b Médias com diferentes sobrescritos são significativamente diferentes $(\mathrm{P}<0.05)$ estimado pela Analise de variância e Teste Tukey. 
SPGA e PQ $(r=0,72, \mathrm{P}<0,05)$; SPGA e CS $(\mathrm{r}=0,93, \mathrm{P}<0,01)$; $\mathrm{PL} / \mathrm{L}$ e CS $(\mathrm{r}=0,88, \mathrm{P}<0,01)$; $\mathrm{PQ}$ e SPDAr $(\mathrm{r}=0,80, \mathrm{P}<0,01)$; $\mathrm{PQ}$ e CS $(\mathrm{r}=0,78, \mathrm{P}<0,01)$ e SPDAr e CS $(\mathrm{r}=0,67, \mathrm{P}<0,05)$. $\mathrm{Na}$ fase púbere houve correlação apenas entre SPGA e $\mathrm{PQ}(\mathrm{r}=0,67, \mathrm{P}<0,05)$; na pós-púbere 1 entre $\mathrm{PL} / \mathrm{L}$ e $\mathrm{PQ}$ $(\mathrm{r}=0,70, \mathrm{P}<0,05)$ e na pós-púbere 2 entre $\mathrm{PL} / \mathrm{L}$ e $\mathrm{PQ}(\mathrm{r}=$ $-0,65, \mathrm{P}<0,05)$.

Quadro 2. Quantificação de espermatogônias A, espermatócitos primários em pré-leptóteno/leptóteno e paquíteno e espermátides arredondadas em relação ao total células espermatogênicas em túbulos seminíferos de cobaios (Cavia porcellus) nas fases pré-púbere tardia, púbere e pós-púbere do desenvolvimento sexual

\begin{tabular}{|c|c|c|c|c|}
\hline & $\begin{array}{l}\text { Pré-púbere } \\
\text { tardia }\end{array}$ & Púbere & $\begin{array}{c}\text { Pós- } \\
\text { púbere } 1\end{array}$ & $\begin{array}{c}\text { Pós- } \\
\text { púbere } 2\end{array}$ \\
\hline & $7,42 \%^{a}$ & $4,91 \% \%^{a}$ & 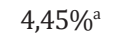 & $\%^{\mathrm{a}}$ \\
\hline $\begin{array}{l}\text { Espermatócito primário } \\
\text { em pré-Leptóteno/Leptóteno }\end{array}$ & & & $\%^{a}$ & $13,97 \%{ }^{a}$ \\
\hline $\begin{array}{l}\text { Espermatócito primário } \\
\text { em paquíteno }\end{array}$ & $41,71 \% \%^{\mathrm{a}}$ & $22,71 \%{ }^{\mathrm{a}}$ & $28,75 \%{ }^{\mathrm{a}}$ & $25,26 \%{ }^{\mathrm{a}}$ \\
\hline Espermátide arredondada & $36,81 \%^{a}$ & $59,44 \%^{\mathrm{b}}$ & $52,85 \%^{\mathrm{b}}$ & $55,34 \%^{\mathrm{b}}$ \\
\hline
\end{tabular}

Médias com diferentes sobrescritos são significativamente diferentes $(\mathrm{P}<0.05)$ estimado pela Analise de variância e Teste Tukey.

Quadro 3. Quantificação de espermatócitos primários em pré-leptóteno/leptóteno ( $\mathrm{PL} / \mathrm{L}$ ) e paquíteno ( $\mathrm{PQ}$ ) em relação ao total de espermatócitos primários em $\mathrm{PL} / \mathrm{L}+\mathrm{PQ}$ em cobaios (Cavia porcellus) nas fases pré-púbere tardia, púbere e pós-púbere do desenvolvimento sexual

\begin{tabular}{lcccc}
\hline & $\begin{array}{c}\text { Pré-púbere } \\
\text { tardia }\end{array}$ & Púbere & $\begin{array}{c}\text { Pós- } \\
\text { púbere 1 }\end{array}$ & $\begin{array}{c}\text { Pós- } \\
\text { púbere 2 }\end{array}$ \\
\hline Espermatócitos em PL/L & $25,21 \%^{\mathrm{a}}$ & $36,30 \%^{\mathrm{a}}$ & $32,67 \%^{\mathrm{a}}$ & $39,23 \%^{\mathrm{a}}$ \\
Espermatócitos em PQ & $74,79 \%^{\mathrm{b}}$ & $63,70 \%^{\mathrm{b}}$ & $67,33 \%^{\mathrm{b}}$ & $64,40 \%^{\mathrm{b}}$
\end{tabular}

Médias com diferentes sobrescritos são significativamente diferentes $(\mathrm{P}<0.05)$ estimado pela Analise de variância e Teste Tukey.

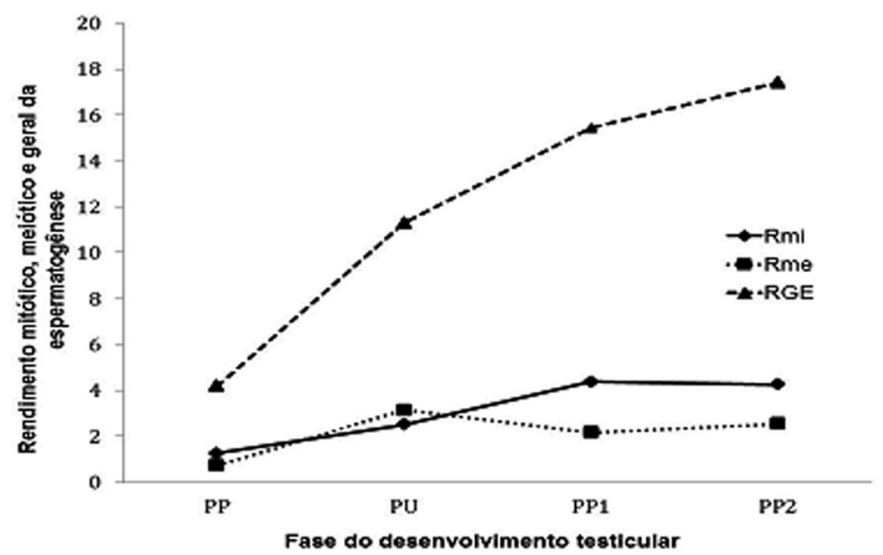

Fig.1. Rendimento das mitoses espermatogoniais (RMi); rendimento das meioses espermatogoniais (RMe) e rendimento geral da espermatogênese (RGE) em cobaios nas fases pré-púbere tardia (PT), púbere (PU) e pós-púbere (PP) do desenvolvimento sexual.

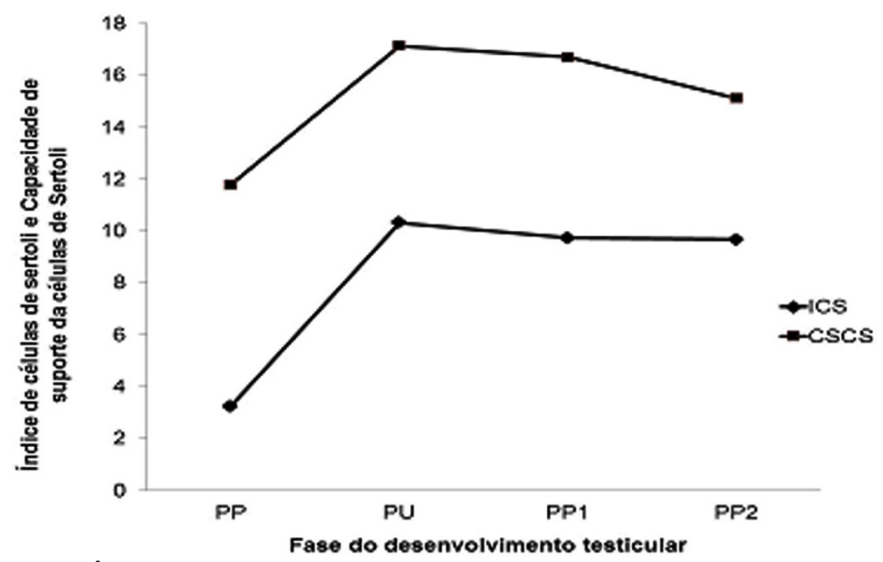

Fig.2. Índice (ICS) e capacidade de suporte (CSCS) das células de Sertoli em cobaios nas fases pré-púbere tardia (PT), púbere (PU) e pós-púbere (PP) do desenvolvimento sexual.

Quadro 4. Razões celulares espermatogênicas de cobaios (Cavia porcellus) nas fases pré-púbere tardia, púbere e pós-púbere do desenvolvimento sexual

\begin{tabular}{ccccccc}
\hline \multirow{2}{*}{$\begin{array}{c}\text { Idade } \\
\text { (semanas) }\end{array}$} & $\begin{array}{c}\text { Desenvolvimento } \\
\text { testicular } \\
\text { (fases) }\end{array}$ & $\begin{array}{c}\text { Rendimento } \\
\text { mitótico } \\
\text { PL/L:SPGA }\end{array}$ & $\begin{array}{c}\text { Rendimento } \\
\text { meiótico } \\
\text { SPDAr:PQ }\end{array}$ & $\begin{array}{c}\text { Rendimento geral da } \\
\text { espermatogênese } \\
\text { SPDAr: SPGA }\end{array}$ & $\begin{array}{c}\text { ICS } \\
\text { SPDAr:CS }\end{array}$ & $\begin{array}{c}\text { CSCS } \\
\text { CE:CS }\end{array}$ \\
\hline S5 & Pré-púbere & $1,25^{\mathrm{b}}$ & $0,73^{\mathrm{b}}$ & $4,19^{\mathrm{b}}$ & $3,24^{\mathrm{b}}$ & $11,78^{\mathrm{d}}$ \\
S6 & Púbere & $2,51^{\mathrm{ab}}$ & $3,14^{\mathrm{a}}$ & $11,29^{\mathrm{ab}}$ & $10,32^{\mathrm{a}}$ & $17,14^{\mathrm{a}}$ \\
S9 & Pós-púbere 1 & $4,38^{\mathrm{a}}$ & $2,17^{\mathrm{a}}$ & $15,43^{\mathrm{a}}$ & $9,73^{\mathrm{a}}$ & $16,69^{\mathrm{b}}$ \\
S11 & Pós-púbere 2 & $4,26^{\mathrm{a}}$ & $2,55^{\mathrm{a}}$ & $17,42^{\mathrm{a}}$ & $9,67^{\mathrm{a}}$ & $15,11^{\mathrm{c}}$
\end{tabular}

$\overline{a, b, c, d}$ Médias com diferentes sobrescritos são significativamente diferentes $(\mathrm{P}<0.05)$ estimado pela Analise de Variância e Teste Tukey. IC: Índice de células de Sertoli e CSCS: Capacidade de suporte das células de Sertoli.

\section{DISCUSSÃO}

0 estabelecimento da espermatogênese é um fenômeno longo e progressivo em que são distinguidas as seguintes fases após o nascimento: impúbere, pré-púbere inicial, pré-púbere tardia, púbere, pós-púbere e de maturidade sexual (Courot et al. 1970). Em cobaios, a morfologia das células espermatogênicas e de Sertoli foi semelhante à descrita para mamíferos em geral (Courot et al. 1970, Assis-Neto et al. 2003b), de modo que na semana cinco de idade os elementos celulares observados indicaram a fase pré-púbere tardia, na semana 6 a fase púbere e nas semanas nove e onze as fases pós-púbere 1 e 2 , respectivamente.

Para o entendimento do processo espermatogênico torna-se essencial o estudo quantitativo das células que compõem o epitélio seminífero, pois possibilita avaliar a espermatogênese determinando seu rendimento intrín- 
seco e também o acompanhamento quantitativo da evolução de cada tipo celular ao longo do ciclo espermatogênico (Cardoso 2009), permitindo a identificação das causas potenciais de infertilidade e subfertilidade, assim como a compreensão dos processos que definem a capacidade de produção espermática (Aguiar et al. 2006). Neste estudo, o valor médio das espermatogônias tipo A apresentou-se constante após a puberdade, como observado em camundongos e caititus (Cardoso 2009) e outros mamíferos (Assis-Neto et al. 2003a). Em termos médios, os valores observados neste trabalho foram superiores ao número obtido por catetos (Costa et al. 2004) e caititus (Cardoso 2009) e inferiores aos de cutias (Dasyprocta aguti, Assis-Neto et al. 2003), ratos Wistar (Almeida et al. 2000; Moura et al. 2006), camundongos (Morais et al. 2009) e preás (Santos et al. 2012).

A população de espermatócitos primários em pré-leptóteno/leptóteno aumentou discretamente da pré-puberdade tardia até a pós-puberdade 2 e a de espermatócitos primários em paquíteno oscilou neste período, indicando que estas populações celulares não estavam estabilizadas após a puberdade, concordando com o relatado em cutias (Assis-Neto et al. 2003a) e caititus (Cardoso 2009). Comparando-se os valores médios destas células com os números obtidos em cutias (Assis-Neto et al. 2003); catetos (Costa et al. 2004); caititus (Cardoso 2009); ratos Wistar (Almeida et al. 2000, Moura et al. 2006); camundongos (Morais et al. 2009) e preás (Santos et al 2012) verificou-se valores inferiores em cobaios.

Espermátides arredondadas apresentaram um crescimento significativo da pré-puberdade a puberdade e um crescimento gradual na pós-puberdade como descrito em cutias (Assis-Neto et al. 2003a) e caititus (Cardoso 2009), isto nos permitiu concluir que, até a pós-puberdade 2 os cobaios não haviam atingido a maturidade sexual. Os valores médios destas células em cobaios foram inferiores aos obtidos em outros roedores (Almeida et al. 2000; Assis-Neto et al. 2003, Costa et al. 2004; Moura et al. 2006; Cardoso 2009 e Santos et al. 2012).

Células de Sertoli apresentaram características de maturidade desde a pré-puberdade tardia, pois seus valores não apresentaram diferença significativa até a pós-puberdade 2. Este fato ocorre porque a diferenciação das células de Sertoli inicia-se logo após a diferenciação gonadal e termina antes da puberdade em todas as espécies de mamíferos investigadas até o momento (Sharpe et al. 2003; Plant et al. 2005). Assim, considera-se que a proliferação de células de Sertoli termina próximo do período de desenvolvimento da barreira de células de Sertoli, da secreção de fluido tubular (com consequente formação do lume tubular), do desenvolvimento do citoesqueleto de actina nas células de Sertoli e da extensa proliferação de espermatócitos primários e espermátides (França et al. 2000, Leal \& França 2008, Avelar 2010). Além disso, a saída das células de Sertoli da fase proliferativa coincide também com o aumento do seu volume nuclear (Avelar 2010), como observado neste estudo. Por isto estes parâmetros são considerados bons indicadores da diferenciação/maturação da célula de Sertoli (Leal \& França 2008). Em cobaios a parada da proliferação das células de Sertoli (na semana 5 de idade) e o estabelecimento da puberdade (na semana 6 de idade) ocorreram mais precocemente do que em chinchila (2 meses e 3 meses, respectivamente, Leal \& França 2008). 0 discreto aumento observado na pós-puberdade 2 também foi descrito em cutias (Assis-Neto et al. 2003a) e opôs-se a caititus cujos valores foram decrescentes da fase impúbere até a pós-puberdade 2 (Cardoso 2009). Em outros roedores (Almeida et al. 2000, Assis-Neto et al. 2003, Costa et al. 2004, Cardoso 2009, Moura et al. 2006, Santos et al 2012) os valores médios das células de Sertoli foram superiores aos obtidos por cobaios. A quantificação das diferentes células espermatogênicas em cobaios na pré-puberdade indicou uma presença menor de espermatócitos primários em PL/L (25,21\% do total de espermatócitos em PL/L+PQ) comparado com espermatócitos primários em LP e Z de cobaios Dunkin Hartley adultos (51,8\%; Rodríguez \& Wettstein 2004). Por outro lado na pós-puberdade 2 houve presença maior tanto em relação ao total de células espermáticas $(13,97 \%)$ quanto ao total de espermatócitos em PL/ L+PQ $(39,23 \%)$ comparado com os achados de Rodríguez \& Wettstein (2004) $(5,5 \%$ das células totais e $24,4 \%$ do total de espermatócitos) e de Bellve' et al. (1977) em camundongos (3,8\% e 16,4\%, respectivamente). Estes resultados indicaram que cobaios na pós-puberdade 2 são ideais para abordar estudos sobre espermatócitos em PL/L, pois este estágio foi altamente representativo $(25,21 \%$ a $39,23 \%$ das células totais) nos túbulos seminíferos comparado com outros roedores.

Na pré-puberdade tardia, embora tenha sido observada correlação positiva significativa entre espermatogônias A e espermatócitos I em PL/L e PQ, não houve correlação das mesmas com as espermátides arredondadas. Estes achados indicaram que a espermatogênese ainda não estava completamente estabelecida e confirmaram que houve perdas nestas etapas iniciais da espermatogênese. Por outro lado, a correlação positiva significativa observada entre todos os tipos de células espermatogênicas e as células de Sertoli, indicou que a capacidade de suporte das células de Sertoli ainda não estava estabelecida, pois estas populações de células germinativas ainda não estavam estabilizadas.

Após a puberdade, a espermatogênese torna-se um processo contínuo e apresenta três fases distintas, a mitótica, a meiótica e a espermiogênese (Courot et al. 1970). Uma forma bastante acurada de se estimar o coeficiente de eficiência do processo espermatogênico é estabelecer as razões numéricas entre os tipos celulares por secção transversal de túbulos. Com isto pode-se fazer comparações entre diferentes espécies, pois é possível localizar as fases onde ocorrem perdas celulares e quantificá-las em termos percentuais (Costa et al. 2004). Assim, a eficiência do processo espermatogênico está dividida em rendimento mitótico, rendimento meiótico e rendimento geral. 0 rendimento mitótico, que representa o número de espermatócitos I em pré-leptóteno/leptóteno derivados de cada espermatogônia do tipo A, se mostrou crescente da pré-puberdade tardia até a pós-puberdade 1, opondo-se ao observado em cutias (Assis-Neto et al. 2003a). Em cobaios o rendimento mitótico foi menor que o de pacas (Carretta Júnior 2008), 
catetos (Costa et al. 2004) e ratos Wistar (Takashiba et al. 2001), e similar na puberdade e superior na pós-puberdade ao de cutias (Assis-Neto et al. 2003). Partindo-se do pressuposto de que cobaios possuem seis gerações de espermatogônias diferenciadas, como a maioria das espécies (França \& Russell 1998), cada espermatogônia do tipo A1 deveria produzir 64 espermatócitos I em pré-leptóteno/ leptóteno, caso o rendimento destas divisões mitóticas fosse de $100 \%$. Deste modo, 2,51; 4,38 e 4,26 células representariam apenas 3,9\%, 6,8\% e 6,6\% do número teoricamente esperado indicando perdas de $96,1 \%$ na puberdade, $93,2 \%$ na pós-puberdade 1 e 93,4\% na pós-puberdade 2, as quais foram próximas às de ratos Wistar (Takashiba et al. 2001) na pós-puberdade; superiores às de pacas (Carretta Júnior 2008) e catetos (Costa et al. 2004) e inferiores às de cutias (Assis-Neto et al. 2003a). Estes achados confirmaram a observação de que as maiores perdas celulares do processo espermatogênico ocorrem durante as mitoses espermatogoniais, as quais podem variar de 60 a $90 \%$ na maioria dos animais (Carretta Júnior 2008).

Por outro lado, o rendimento meiótico, representado pela razão de espermátides arredondadas por espermatócitos I em paquíteno, aumentou de modo significativo na puberdade e depois diminuiu na pós-puberdade 1 e 2 . Nossos valores na puberdade foram semelhantes aos de rato espinhoso sexualmente maduro (Cordeiro-Júnior et al. 2010) e na pós-puberdade 2 próximos aos de pacas (Carretta Júnior 2008); catetos (Costa et al. 2004) e ratos Wistar (Takashiba et al. 2001) e inferiores aos de cutias (Assis-Neto et al. 2003). Neste estudo, cada espermatócito I em paquíteno, gerou, em média, $78,5 \%, 54,2 \%$ e $63,7 \%$, respectivamente, do valor teoricamente esperado de espermátides arredondadas/espermatozóides (1:4) caso o rendimento da espermatogênese fosse $100 \%$, tendo as perdas de espermátides/espermatozóides sido, respectivamente, de $21,5 \%, 45,7 \%$ e $36,2 \%$. As perdas durante as meioses espermatogoniais variam de 5 a 30\% na maioria dos animais domésticos e se constituem num mecanismo de eliminação de células com cromossomos anormais ou aberrações (França \& Russell 1998) e para limitar o número de células germinativas a uma quantidade passível de ser suportada pelas células de Sertoli (Costa \& Paula 2006). Em cobaios as perdas durante a meiose ficaram dentro do limite esperado para animais domésticos na puberdade e acima deste na pós-puberdade 1 e 2 .

0 rendimento geral da espermatogênese representa o número de espermátides arredondadas derivadas de cada espermatogônia A e é um indicativo importante da capacidade de produção espermática, podendo servir como parâmetro na determinação da idade ideal para a entrada em serviços de reprodução. De modo geral, este rendimento cresce gradualmente após a puberdade e depois se estabiliza por ocasião da maturidade sexual (Assis-Neto et al. 2003a). Em cobaios o rendimento geral da espermatogênese aumentou continuamente da puberdade até a pós-puberdade 2, sem apresentar sinais de estabilidade, fato que confirmou que a maturidade sexual não havia se estabelecido até a pós-puberdade 2 concordando com os achados em cutias (Dasyprocta sp., Ferreira 2002, e Dasyprocta aguti, Assis-Neto et al. 2003a). 0 rendimento geral da es- permatogênese em cobaios foi similar ao de ratos Wistar (Takashiba et al. 2001), pacas (Carretta Júnior 2008) e cutias (Ferreira 2002) e inferior ao de cutias (Assis-Neto et al. 2003) e catetos (Costa \& Paula 2006) na pós-puberdade 2 . Neste estudo este rendimento foi $6,8 \%$ do teoricamente esperado, pois se não houvesse perdas durante este processo, cada espermatogônia A teria gerado 256 espermátides arredondadas/espermatozóides. Assim, as perdas no processo espermatogênico foram de aproximadamente $93,2 \%$, bem superior à descrita como a esperada para mamíferos (França \& Russell 1998) e catetos (Costa \& Paula 2006) e similar a de ratos Wistar (Takashiba et al. 2001) e cutias (Ferreira 2002). Segundo França \& Russell (1998), estas perdas parecem ser um mecanismo que limita o número de células germinativas a uma quantidade que pode ser suportada pelas células de Sertoli disponíveis, por isso é que, mesmo em espécies com alta produção espermática elas podem ser tão altas quanto $70 \%$.

Células de Sertoli são fundamentais na regulação do processo espermatogênico, pois entre suas funções estão o suporte e a nutrição das células germinativas em desenvolvimento, a compartimentalização do epitélio seminífero, a liberação de espermatozóides no lume tubular, a secreção de fluidos e proteínas, a fagocitose de células germinativas em degeneração e do excesso de citoplasma das espermátides em espermiação (França \& Russell 1998). A população de células de Sertoli no epitélio seminífero é constante ao longo de toda a vida do animal e, em cada espécie, apresentam capacidade para suportar um número limitado de células germinativas (França \& Russell 1998), conhecido como índice de célula de Sertoli. Este índice tem sido utilizado como um bom parâmetro para avaliar a eficiência reprodutiva, pois quando a relação células de Sertoli:espermátides arredondadas é alta, a produção espermática diária também é (França \& Russell 1998). Encontraram-se 10,32 espermátides arredondadas para cada célula de Sertoli na puberdade, valor que apesar de semelhante ao encontrado em caititus (Cardoso 2009) é ligeiramente mais baixo que o de catetos (Costa et al. 2004); pacas (Carretta Júnior 2008); rato espinhoso (Cordeiro-Júnior et al. 2010) e preás (Santos et al. 2012), e mais alto que o de cutias (Assis-Neto et al. 2003a), ratos Wistar (Moura et al. 2006) e da maioria dos animais domésticos (França \& Russell 1998). A diminuição observada na pós-puberdade 2 em cobaios concordou com Assis-Neto et al. (2003a) e Cardoso (2009), reforçando que até a pós-puberdade 2 os cobaios ainda não haviam atingido a produção espermática diária máxima.

As células de Sertoli possuem capacidade limitada de suporte estrutural e nutricional para as células germinativas, sendo esta característica espécie-específica e definida após a puberdade, quando todas as células germinativas já estão formadas no interior dos túbulos seminíferos (França et al.2000). Para avaliar a capacidade de suporte das células de Sertoli foi calculada a razão entre o número das células de Sertoli e o número total das células espermatogênicas por secção transversal de túbulos seminíferos, tendo sido observados valores de 17,14; 16,69 e 15,11 na puberdade e pós-puberdade 1 e 2 , respectivamente. 0 número total de células germinativas suportado por cada célula de Sertoli 
no estádio 1 do ciclo do epitélio seminífero foi superior a suportada por cutias (Ferreira 2002) e ratos Wistar (Moura et al. 2006) e inferior a catetos (Costa et al, 2004) e pacas (Carretta Júnior 2008), evidenciando que as células de Sertoli de cobaios têm uma eficiência funcional maior que a de cutias e ratos Wistar e menor que a de catetos e pacas.

Os resultados demonstram que Cavia porcellus na fase pós-púbere são um modelo experimental vantajoso para realização de estudos sobre os processos de reconhecimento homólogo, alinhamento e sinapse durante a prófase da meiose; o rendimento intrínseco da espermatogênese de cobaios é semelhante ao de ratos Wistar, pacas e cutias (Dasyprocta sp.) e inferior ao de preás, enquanto que a eficiência funcional das células de Sertoli é superior à de cutias e ratos Wistar e inferior à de catetos e pacas. Conclui-se que em cobaios a espermatogênese está completamente estabelecida na semana 6 de idade, indicando a fase púbere do desenvolvimento sexual, e que até a semana 11 estes não haviam atingido a produção espermática diária máxima e, portanto, a maturidade sexual.

Agradecimentos.- Ao Programa de Iniciação Científica (PIBIC/CNPq UNIVASF) pelas bolsas.

\section{REFERÊNCIAS}

Abercrombie M. 1946. Estimation of nuclear population from microtome sections. Anat. Rec. 49:238-248.

Aguiar G.V., Araujo A.A. \& Moura A.A.A. 2006. Desenvolvimento testicular, espermatogênese e concentrações hormonais em touros Angus. Revta Soc. Bras. Zootec. 35(4):1629-1638.

Almeida L.M., Weiss R.R., Castro C.S. \& Büchele J. 2000. Quantificação histológica da espermatogênese de ratos Wistar tratados com dimetil sulfóxido. Arch. Vet. Sci. 5:129-135.

Amann R.P. 1962. Reproductive capacity of dairy bulls. IV. Spermatogenesis and testicular germ cell degeneration. Anim. J. Anat. 110:69-78.

Assis-Neto A.C., Melo M.I.V., Carvalho M.A.M., Miglino M.A. \& Oliveira M.F. 2003a. Quantificação de células dos túbulos seminíferos e rendimento da espermatogênese em cutias (Dasyprocta aguti) criadas em cativeiros. Braz. J. Vet. Anim. Sci. 40:175-179.

Assis-Neto A.C., Melo M.I.V., Carvalho M.A.M., Miglino M.A., Oliveira M.F., Menezes D.J.A., Papa P.C. \& Kfoury Júnior J.R. 2003b. Análise qualitativa do estabelecimento da espermatogênese em cutias (Dasyprocta aguti) criadas em cativeiros. Braz. J. Vet. Res. Anim. Sci. 40:180-184.

Avelar G.F. 2010. Análises morfométrica e funcional das células somáticas do testículo de suínos durante o desenvolvimento pós-natal. Tese de Doutorado, Universidade Federal de Minas Gerais, Belo Horizonte, MG. 114p.

Cardoso D.L. 2009. Puberdade em caititus (Tayassu tajacu): estudo da espermatogênese em diferentes faixas etárias. Dissertação de Mestrado em Ciência Animal, Universidade Federal do Pará, Bélem, PA. 73p.

Carretta Júnior M. 2008. Avaliação morfofuncional do processo espermatogênico de pacas (Cuniculus paca Linnaeus, 1766) adultas. Dissertação de Mestrado, Universidade Federal de Viçosa, Viçosa, MG. 61p.

Cordeiro-Júnior D.A., Costa G.M.J., Talamoni S.A. \& França L.R. 2010. Spermatogenic efficiency in the spiny rat, Trinomys moojeni (Rodentia: Echimyidae). Anim. Reprod. Sci. 119:97-105.

Costa D.S. \& Paula T.A.R. 2006. Cinética da espermatogênese de catetos (Tayassu tajacu). Revta Ceres 53:515-522.

Costa D.S., Henry M. \& Paula T.A.R. 2004. Espermatogênese de catetos (Tayassu tajacu). Arq. Bras. Med. Vet. Zootec. 56:46-51.
Courot M., Hochereau-De-Reviers M.T. \& Ortavant R. 1970. Spermatogenesis, p.339-432. In: Johnson A.D., Gomes W.R. \& Vandemark N.L. (Eds), The Testis. Academic Press, New York.

Ferreira A.V., Vasconcelos A.L. \& Bruna E.M. 2007. Efeito da remoção de sementes por formigas aves e roedores no recrutamento de plântulas no cerrado. Biológico, São Paulo, 69:359-363.

Ferreira A.C.S. 2002. Determinação de puberdade em cutias (Rodentia: Dasyproctidae) criadas em cativeiro, através da quantificação das células espermatogênicas. Dissertação de Mestrado em Zoologia, Universidade Federal do Pará, Belém, PA. 78p.

França L.R., Silva Jr V.A.S., Chiarinegarcia H., Garcia S.K. \& Debeljuk L. 2000. Cell proliferation and hormonal changes during postnatal development. Biol. Reprod. 63:1629-1636.

França L.R. \& Russell L.D. 1998. The testis of domestic animals, p.197-219. In: Martinez-Garcia F. \& Regadera J. (Eds), Male Reproduction: a multidisciplinary overview. Churchill Livingstone, Madrid.

Gradela A., Martins L.F.T., Nunes A.K.R., Santos J.M., Lins T.L. B., Menezes V.G. \& Franzo V.S. 2012. Morphologic and morphometric aspects of the vesicular gland during development in guinea pigs (Cavia porcellus). Anais $8^{\text {th }}$ Assoc. Appl. Anim. Androl. Bien. Conf. "Quality Assurance and Biosecurity in the Globalized Andrology Lab", Vancouver, Canada. Disponível em <http://www.ivis.orgproceedingsaaaa2012Gradela.pdf>

Leal M.C. \& França LR. 2008. Postnatal Sertoli and Leydig cell proliferation and the establishment of puberty and sexual maturity in Chinchilla lanigera (Rodentia, Chinchillidae). Reprod. Fertil. Dev. 20:665-673.

Morais A.C.T., Barbosa L.P., Neves M.M., Matta S.L.P., Morais D.B. \& Melo B.E.S. 2009. Parâmetros morfofisiológicos testiculares de camundongos (Mus musculus) suplementados com geleia real. Arq. Bras. Med. Vet. Zootec. 61:110-118.

Moura C.S., Guerra M.M.P., Silva Júnior V.A., Silva C.G.C., Caju F.M. \& Alves L.C. 2006. Avaliação histomorfométrica do parênquima testicular de ratos adultos tratados com diferentes doses de ivermectina. Arq. Bras. Med. Vet. Zootec. 58:799-808.

Myers P. 2000. "Rodentia”. Animal Diversity Web. University of Michigan Museum of Zoology. Disponível em <http://animaldiversity.ummz.umich.edu/site/accounts/information/Rodentia.html> Acessado em 20 mar. 2010

Plant T.M., Ramaswamy S., Simorangkir D. \& Marshall G.R. 2005. Postnatal and pubertal development of the rhesus monkey (Macaca mulatta) testis. Ann. N.Y. Acad. Sci. 1061:149-62.

Rodríguez R.E. \& Wettstein R.M. 2004. Quantitative study on guinea pig spermatogenesis shows a relative high percentage of early meiotic prophase stages. Anat. Rec. A 278A:493-504.

Santos P.R.S., Oliveira M.F., Silva A.R. \& Assis Neto A.C. 2012. Development of spermatogenesis in captive-bred Spix's yellow-toothed cavy (Galea spixii). Reprod. Fertil. Develop. 24:877-885.

Sharpe R.M., McKinnell C., Kivlin C. \& Fisher J.S. 2003. Proliferation and functional maturation of Sertoli cells, and their relevance to disorders of testis function in adulthood. Reproduction 125:769-784.

Silva J.R.V., Báo S.N., Lucci C.M., Carvalho F.C.A,. Andrade E.R., Ferreira M.A.L. \& Figueiredo J.R. 2001. Morphological and ultrastructural changes occurring during degeneration of goat preantral follicles preserved in vitro. Anim. Reprod. Sci. 66:209-223.

Suzuki O., Koura M., Noguchi Y., Takano K., Yamamoto Y. \& Matsuda J. 2003. Optimization of superovulation induction by human menopausal gonadotrophin in guinea pigs based on follicular waves and FSH-receptor homologies. Mol. Reprod. Develop. 64:219-225.

Takashiba K.S., Segatelli T.M., Moraes S.M.F. \& Natali M.R.M. 2011. Morfologia testicular de ratos Wistar obesos sedentários e submetidos a treinamento físico. Acta Scient. Health Sci. 33:25-33.

Vásquez B. \& Del Sol M. 2010. Estudio morfológico de la próstata y glándulas vesiculares de Cobayo (Cavia porcellus). Int. J. Morphol 28:13011307. 